\title{
A Study of Subtitle Translation from the Perspective of Skopos Theory: Youth Film as a Case Study
}

\author{
Lyu Liangqiu, Wang Donghui \\ School of Foreign Languages, North China Electric Power University, Beijing, China \\ Email address: \\ 1lq2803@163.com (Lyu Liangqiu),674790016@qq.com (Wang Donghui)
}

To cite this article:

Lyu Liangqiu, Wang Donghui. A Study of Subtitle Translation from the Perspective of Skopos Theory: Youth Film as a Case Study. International Journal of Applied Linguistics and Translation. Vol. 4, No. 2, 2018, pp. 26-30. doi: 10.11648/j.ijalt.20180402.11

Received: May 7, 2018; Accepted: July 3, 2018; Published: July 26, 2018

\begin{abstract}
With the increasing influence of movies in the world, subtitle translation plays an indispensable role in appreciating them. Based on the theoretical framework of skopos theory, this article uses the subtitles of the film "Youth" and their translations as the corpus. The goal is to maximize the audience's understanding of the source film lines. It combines interpretation, abbreviation, supplementary and substitution methods together. The different functions of film lines are employed to study subtitle translation. Analyzing the function of movie lines not only helps to clarify the intended functions of the translation, but also provides ideas for subtitle translation.
\end{abstract}

Keywords: Film, Skopos Theory, Subtitle Translation, Youth

\section{Introduction}

Youth is adapted from the novel of the same name by the Chinese-American female writer Yan Geling. The film is based on the background of China from the 1970s to the 1980s. It tells the story of a troop of youth, who are full of ideals and passion. The film explores in depth the individual strength and destiny of the individual under the era of collectivism, and uses the stories of Liu Feng and He Xiaoping as two characters to admire and praise the "truth, goodness, and beauty" of human nature (Liu, W., 2018, p. 92). As for the background, there are the events of the Cultural Revolution, the Sino-Vietnamese War and other realities in China, and therefore it is full of Chinese elements. The film is released simultaneously in China and North America on December 15, 2017. At the first Saipan International Film Festival Awards Ceremony, Youth won the Best Film Award. In addition to the actor's solid acting skills and vivid scenes, the translation of authentic English subtitles also played a pivotal role in cross-cultural communication.

As a special art method in film, subtitle translation is different from other applied translations such as science and technology translation. Looking at the major schools of translation theory and their characteristics, the skopos theory is the most felicitous one. From the perspective of it, the translation behavior is the most important objective, which predetermines the translator's translation strategies to convey the source text's function, that is to say, whether the translation is easier for the target language reader to accept and understand. According to the operational report of the China Translators Association, "the Chinese Translation Association has responded to the situation and has opened up innovations and positive actions in the development of foreign translation and discourse systems" (Li, Y. X., 2001, p. 38). The establishment of a discourse system requires that the other side understands the meaning of the discourse correctly, and both sides actively engage in communicative activities. "Going out of today's Chinese culture has been promoted to the height of the national strategy, and pushing Chinese culture to the world is not just a matter of translation of a simple cultural word itself" (Wang, Q. W., 2015, p. 100). It can be seen under the guidance of the general secretary's "cultural self-confidence" spirit. According to China's new policy, it must keep up with the pace of the times in film production. Its goal is to use the film and television arts to make good use of Chinese stories and promote its own culture and ideas. In the following, this article will use the film Youth as a case study to analyze the application of skopos theory in subtitle translation. 


\section{Overview of Skopos Theory}

As early as in the ancient times, people asked what kind of translation methods should be adopted in different types of texts. With the development of the times, various schools of thoughts have emerged in different regions and periods. Skopos theory is the core of the functionalist translation theories; it was developed in Germany in the 1970s. It is considered as a new trend of looking at translation, in which translation is no longer limited to conventional source-text oriented views (Du, X. Y., 2012, p. 2190). Firstly, it was put forwarded by Hans Josef Vermeer, who was the German linguist and translation scholar. Vermeer used to be Reiss's student, but he disagreed with his teacher in that Reiss held the linguistic-oriented view on translation. Reiss believes that translation is "a type of transfer where communicative verbal and non-verbal signs are transferred from one language into another" (Nord, C., 2001, p. 29). However, Vermeer considers translation as a sort of human performance with the aim and prospect in a given situation. From the skopos theory's view that "the way in which the target text eventually shape up is determined to a great extent by the function, or 'skopos', intended for it in the target context" (Hatim, B., 2005, p. 74). Therefore, the goal or purpose of a translation determines the methods, techniques and process of translation so as to realize a functionally adequate translation (Zhao, Y. S. \& Jiang, Y. W. 2014, P. 9). In the second stage, Justa Holz-Mänttäri develops Vermeer's theory based on the action theory (Ma H. J., Miao J., 2016, p. 82). Moreover, she regards translation as a form of cross-cultural event instead of a dull source-target translation process. In her thoughts, translation is defined as an act of carrying messages among different cultures and getting over the obstacles of the cross-cultural communication. In the third stage, Nord mentions the formers' opinions about skopos theory in her famous work Translation as a Purposeful Activity: Functionalist Approaches Explained. She holds the view that "function refers to the factors that make a target text work in the intended way in the target situation. Loyalty refers to the interpersonal relationship between the translator, the source-text sender, the target-text addressees and the initiator" (Nord, C., 2001, p. 126).

In 1978, Vermeer laid down three principles in the skopos theory, which are the skopos rule, coherence rule and fidelity rule. Among the three rules, the skopos rule is the primary principle of translation, and the fidelity rule is subordinate to the coherence rule, and both are subject to the first rule. Therefore, the internal coherence of the translated text and the realization of the fidelity to the source text depend mainly on the purpose of translation.

\section{Application of Skopos Theory into the Translation of Youth Film}

Youth tells the story of the Chinese Art Troupe in the 70s and 80s. It has strong Chinese characteristics and meets the criteria for China's foreign film promotion. In particular, many subtitles with unique Chinese elements are suitable for using the translation methods from the functionalist translation skopos theory. For this reason, the movie Youth is selected as a case study. Moreover, Skopos theory means that the intended goal of the translation determines the translation strategies. The skopos rule, coherence rule and fidelity rule should be followed in the process of translation. The author proposes four translation strategies, which are interpretation, abbreviation, supplementary, and substitution, to deal with specific problems in the process of translation. The purpose is to explain that the skopos theory of functional schools can be employed in movie translation and contribute to the development of the film industry.

\subsection{Interpretation}

Due to the great differences between Chinese and Western cultures, many Chinese culturally specific vocabularies make it difficult to find the corresponding original vocabulary in English, that is to say, some words do not have corresponding items in the target language. This film also reflects the Cultural Revolution that China experienced after the founding of the People's Republic of China and the history of the Sino-Vietnamese War. For that reason, there are many culturally specific items such as vocabularies and idioms with Chinese characteristics. For such translations, translators should combine cross-cultural differences and, if necessary, interpretative methods should be adopted. The purpose of the subtitle translation in the film is to convey the content of the film to western viewers in a better way. Hence, the interpretation must be more in line with the customary expression of the target audience, that is, the traditional methods of domestication and alienation, but by analyzing movie lines, we can see that the subtitle translation is more inclined to the former.

Example 1.

ST: 你手真巧。

TT: You're got the Midas touch.

"Midas" is a character in Greek mythology, described in the story "Allusion of the Goldfinger". King Midas was the king of Pessinus in Greek myth who prayed God to give him the magic of pointing stone to gold. However, after he learned the magic, he was so greedy that everything around him, including food and beauty, was turned into gold by his fingers. Finally, he hoped that God would restore all the things to their original condition. The film scene here is that the story character Lin Dingding praises Liu Feng's handcrafted sofa for exquisite workmanship. The translator did not directly translate it into "your hands are clever" but carefully considered the target audience. Since the Greek mythical characters are familiar to Westerners, the translator kept the skopos rule in mind that he should explain and respect cross-cultural differences.

Example 2.

$\mathrm{ST}$ : 越说越离谱了啊。

TT: You're getting off track.

“离谱” is a spoken word in Chinese. It means that someone's speech or behavior is different from common people. In English, there is no such word. If it is directly 
translated as "far away from what is normal", it is too ambiguous and hard to use. The skopos rule indicates that translation is influenced by the translational goals. Thus, the translator chose the English phrase "get off" to match with the word "track", which is functionally equivalent to the original, which is authentic and concise, in line with the target language audience's way of thinking. It is clear that the translator kept the skopos rule in mind and revealed the source language's real meaning.

Example 3.

$\mathrm{ST}$ : 当了一个万金油。

TT: And become a jack of all trades.

“万金油” is a kind of folk proverb with metaphorical rhetoric in Chinese. It is used to describe all kinds of talents who can do the job well, and be able to handle problems properly under the emergent situations. It is hard for someone to be able to do this at the same time, so it's just saying that such people are like gold and oil, which is very valuable and useful. Furthermore, there is a similar expression of "all things". Although English does not have a one-to-one correspondence, there are also some folk sayings, like "all work and no play makes Jack a dull boy". Here, the translator chose the expression "Jack of all trades" to translate it, which is familiar to the audience of the target language. According to the coherence rule, the purpose text should be acceptable and meaningful to the target text receiver. Translation is supposed to be valid in communicative context and the culture of the translation language, as well as be understood and known by the receiving readers. The meaning of the expression is accurate and the image is vivid. It also conveys the sense of humor of the film.

\subsection{Abbreviation}

The length of subtitle translation is limited by two major factors, which are space and time. Basil Hatin and Iran Mason once pointed out that "from a spatial point of view, captions on the screen do not exceed two lines, generally up to 33 characters per line. From a time point of view, captions stay on the screen for a minimum of 2 seconds, staying for 7 seconds" (Hatim, B., Mason, I., 1970). Based on this theory, when subtitle translation is performed, it is necessary to be as concise and colloquial as possible, on the premise of ensuring the correct delivery of the original text. Therefore, the abbreviation method is often used to adjust the original text appropriately so as to make the target language audience understand in a better way.

Example 4.

$\mathrm{ST}$ : 进了团不要跟别人说这件事。

TT: Keep quiet about it.

The sentence is uttered when Liu Feng led He Xiaoping into the work group. He told her not to tell others that her own father was still in reeducation. The actor in the movie made the corresponding gesture of whispering. Thus, the subtitle translation can omit it. When combined with the scenes of the scene, it is natural to save unnecessary words and replace it with "keep quiet". It also shows the guiding of the fidelity rule.
Example 5.

ST: 给我让个位置。

TT: Make some room.

This sentence is uttered when everyone is eating dumplings Liu Feng says to the next good friend Ho Sui-zi, omitting the subject "you make some room for me", because on the one hand, it is a dialogue between good friends, on the other hand, using the abbreviations to convey the eagerness that the protagonist cannot wait to think of sitting with the girl Lin Dingding, whom he likes. This translation is good enough to outline the true ideas of the characters. The fidelity rule usually requires the target text to be faithful to the source text. We could clearly see from this example that even though the skopos theory emphasizes the target text and the target receivers, it also considers the original text and the source text. As for the translators, when they translate the texts, they should remember that they can not betray the original author.

Example 6.

ST: 吹吹歪歪的, 一点都不像个男的。

TT: Take it like a man.

“吹吹歪歪” means derogatory in Chinese, which conveys a sense of discontent. This sentence is the dissatisfaction expressed by Hao Shuwen when she argues with Chen Can. Thereupon, in the translation, it only needs to convey the meaning of letting him behave like a man, and at the same time, it helps to show her forthright personality. According to the skopos rule, in the process of translation, expectations, cultural background and acceptability should be taken into account.

\subsection{Supplementary}

Because there are many differences between Chinese and English in grammar, vocabulary and cross-culture, some words or components are often omitted in Chinese. When translating Chinese into English, it is often necessary to supplement the omitted parts in order to make the translation more suitable for the purpose. When subtitles are translated, appropriate additions are often made to facilitate the target audience to better understand the complete meaning conveyed by the lines.

Example 7.

ST: 平时我都是自己烧水用盆擦。

TT: So usually I'd boil water at home for a scrub down.

This sentence is the dialogue between the heroine and He Suizi in the bath. When she first arrived, she thought she had started a kind of new life. After learning that it cost nothing to bathe in here, she said that she used to boil water at home. In order to make it easier for the target language audience to understand and supply the culture difference, the location adjunct of "at home" is added to the translation to make the expression clearer. This example clearly shows the importance of skopos rule in skopos theory, that is, when it appears the conflicts of choosing which rule to guild the translation strategy, the skopos rule is better than the fidelity rule.

Example 8.

$\mathrm{ST}$ : 你看, 现在走得还行。

TT: Look, it runs fine now. 
This scene is explained by Liu Feng to Lin Dingding. There are a large number of non-subject sentences in Chinese, which should be added when translated into English, by appending the subject "it". Here, "it" means the watch which Liu Feng has repaired for the girl he has an affection for. Similarly with example 7, the use of skopos rule is better than the other two.

Example 9.

$\mathrm{ST}$ : 她那胸罩肯定在她身上穿着呐。

TT: She's wearing the bra, I'd bet.

He Xiaoping became the object of jokes for everyone because of the "the accident of stealing uniforms" before. In the face of new scandals, everyone ran against her. Another girl had a strong sense of confidence when she said this ironically. When translating, the translator naturally adds the words "I dare to bet" as provocative words, which helps the target language audience to feel the emotional attitude of the characters. In this utterance, the employing of the coherence rule is better than the fidelity rule.

\subsection{Substitution}

Repetition is a commonly used method of textual cohesion in Chinese. Although there are repetitions in English, most of the repetitions use words to embody semantic emphasis or language retouching. There are more repetitions in Chinese and more omission in English. As a result, when translating Chinese into English, especially in subtitle translation, substitutions can be used to avoid the tediousness of using repetition.

Example 10.

ST: 女演员休息。

TT: Girls, take a break.

This sentence is spoken by the captain during training. In order to convey the vibrant spirit of the actress, the translator avoids translating directly into "The actresses take a break", but describes it by choosing the same function word to express the young female in the target language. The word "girls" is suitable for such expression and it can convey successfully the vivid character of the actresses. The translator kept the coherence rule in mind to convey the same function of the utterance.

Example 11.

ST: 你们几个家在北京的。

TT: All of you Beijingers.

“你们几个家在北京的” is said to indicate the actors who come from Beijing. It is the hero Liu Feng's words to other comrades from Beijing. He went to Beijing to have the meeting and brought the foods to those who are from Beijing. There is no comparable single word already in English to express "people who come from Beijing", so the use of geographical expression vocabulary "Beijing" plus "a certain class of people", which is expressed as the English suffix "-er" to create a new word "Beijinger". At the same time, in Chinese, the number represents the plural number, while in English, the number corresponding to the countable noun is also corresponding to the plural expression. Since translation is the information provided by the source text, the target text should relate to the original forms. Vermeer regards this relationship as "inter-textual coherence" or "fidelity". The fidelity rule requires that the translation should be faithful to the source text. From this example, we can have a better understand of the fidelity rule of skopos theory.

Example 12.

ST: 而猴啊?

TT: A performing monkey?

According to the coherence rule, the success of the translation relies on the comprehension of the target text receiver. Therefore, the translator needs to take the expectations, knowledge and text of the target audience into consideration, for the purpose of making the target text easier to be understood and largely accepted in the target culture. “耍 猴” is a Chinese folk unique entertainment method. It refers to specially trained monkeys imitating people's action performances. This is the scene of the team leader criticizing the cultural group actress that they bully He Xiaoping. This sentence expresses the ironic and sarcastic function. According to its purpose, the verb "playing" means "performance", so "perform" is employed instead of using "play" in translation. Although there is no such word in the West, it is natural to see "monkey's performance" in the circus. In addition, funny scenes are more helpful for Western audiences to understand emotions.

Example 13.

ST: 破饺子也得有人吃啊。

TT: Someone's got to eat the split ones.

The scene of this sentence is that everyone eats dumplings together, Liu Feng Da Gong only selflessly eats the broken dumplings that nobody would like to eat, and "split ones" means "dumplings which are lacking of stuffing". When the speaker utters this sentence, everyone is staring at the dumplings in his bowl, so the substitution strategy is used to translate the subtitles, in line with the principle of saving character space for movie subtitles.

All in all, in terms of film subtitle translation, skopos theory should be used as a guide to clarify the purpose of subtitle translation and try its best to achieve the goal of "translation should be based on the analysis of the original text, and the purpose of the intended function of the translation is to choose the best method" (Zhang, J. L., 2004, p. 35). Besides, from examples analyzed above, the skopos rule is often chosen to decide the translation methods than the coherence rule and fidelity rule in the translation of movie Youth.

\section{Conclusion}

German functionalist theory of translation is one of the classic translation hypotheses, and the skopos theory is its core. Through the analysis of the above examples, we can clearly see the application of skopos theory guiding the film subtitle translation, which has a very effective role in the promotion of China's foreign film-making. Subtitle translation is a purposeful act, which should be the primary principle that highlights our own cultural heritage and characteristics. Properly using of domestication and foreignization, and appropriate additions as well as deletions of vocabulary during 
translating will help achieve this goal. Youth is a successful movie both at home and abroad. Its subtitle translation, the using of interpretation, abbreviation, supplementary, substitution strategies are worthy. So, other translators will learn from these transaltions when they translate Chinese films into foreign languages. In the translation process of subtitles, the translators should combine the intention of the director and the psychological expectations of the target audience in order to further achieve the purpose of cultural exchange.

\section{Acknowledgements}

Supported by "Double First-class" Construction Projects at North China Electric Power University.

\section{References}

[1] Du, X. Y. (2012). A brief introduction of skopos theory. Theory and Practice in Language Studies, 2(10), 2189-2193.

[2] Hatim, B. (2005). Teaching and researching translation. Beijing: Foreign Language Teaching and Research Press.
[3] Hatim, B., Mason, I. (1970). The translator as communicator. London: Rouledge, 1998 Publishers.

[4] Li, Y. X. (2001). The strategy of subtitle translation. Chinese Translators Journal, 4, 38-40.

[5] Liu, W. (2018). The "Youth" year of breaking the silkworm into a butterfly-Analysis of the character image of the film Fanghua. News World, 3: 92-94.

[6] Ma, H. J., Miao, J. (2016). Second readings of contemporary western translation theories. Beijing: Foreign Language Teaching and Research Press.

[7] Nord, C. (2001). Translation as a purposeful activity: Functionalist approaches explained. Shanghai: Shanghai Foreign Language Education Press.

[8] Wang, Q. H. (2015). Chinese culture going out and translation strategy choice in the perspective of communication studies. Foreign Language Education, (3): 100-104.

[9] Zhang, J. L. (2004). Theory and translation methods. Chinese Science \& Technology, 10(3): 35-37.

[10] Zhao, Y. S., \& Jiang, Y. W. (2014). Translation techniques of Chinese union version: from the perspective of skopos theory. Canadian Social Science, 10(3): 9-13. 